References

1 Carle BN. Autofluorescence in the identification of myocardial infarcts. Hum Pathol 1981;12:643-6.

2 Siegel RJ, Fishbein MC. Evaluation of the fluorescence microscopy for the identification of necrotic myocardium. Hum Pathol 1982;13:1091-4.

3 Al-Rufaie HK, Florio RA, Olsen EGJ. Comparison of the haematoxylin basic fuchsin picric acid method and the fluorescence of the haematoxylin and eosin stained sections for the identification of early myocardial infarction. J Clin Pathol 1983;36:646-9.

4 Sahai VB, Knight B. The post-mortem detection of early myocardial infarction by a simple fluorescent method. Med Sci Law 1976;16:17-20.
5 Knight B. Investigation of sudden death from myocardial ischaemia. Forensic Science 1976;8:33-6.

6 Zollinger U. Die Chromotrop-Anilinblau-Faerbung zur besseren Darstellung frischer Herzmuskelfaserschaedigungen. $Z$ Rechtsmed 1983;90:269-75.

7 Rajs J, Jakbsson S. Experiences with the haematoxylin basic fuchsin picric acid staining method for morphological diagnosis of myocardial ischaemia - an experimental study in forensic pathology. Forensic Science 1976;8:37-48.

Requests for reprints to: Dr G Fechner, Department of Forensic Medicine, Clinical Sciences Building, St James's University Hospital, Beckett Street, Leeds LS9 7TF England.

\section{Linear track scanning of pathological tissue sections: an interdisciplinary approach to microscopy}

\author{
J D DAVIES, C C JEAL, A R HOLTON Department of \\ Pathology, University of Bristol, Bristol BS8 1TD, \\ and Department of Chemical Pathology, Bristol Royal \\ Infirmary, Bristol
}

Quantitative assessment of microscopical images may be achieved by manual point counting or more sophisticated stereology, ${ }^{12}$ dedicated microdensitometry, or automated image analysis. ${ }^{3}$ All these methods are either laborious or expensive.

Many changes in biological tissues are not homogeneous but exhibit a distinct polarity. The method described here aims to analyse such anisotropic variation in tissues. It is cheap and simple and gives both qualitative and quantitative evaluation of the optical density of constituents from linear tracks of sectioned tissue. The method entails the use of a photomicroscope and an integrating densitometer, which is designed primarily for the analysis of stained electrophoretic agarose gel tracks of proteins.

The equipment or its equivalent is readily available in most histopathological and chemical pathology laboratories, and thus the method requires no additional capital expenditure. In tightening economic circumstances these are considerable virtues. To illustrate the method we describe an examination of lymph nodes, but clearly there are much wider applications.

\section{Material and methods}

Twenty four lymph nodes from cats ${ }^{4}$ and humans ${ }^{5}$ were fixed in $10 \%$ aqueous formaldehyde, processed through alcohols and toluene, and then embedded in paraffin wax. Sections of $5 \mu \mathrm{m}$ depth were cut on a rotary microtome, stained with Harris's haematoxylin and eosin, dehydrated, and mounted under glass coverslips in DPX.

The stained sections were photographed using a Zeiss Ultraphot III B (West Germany) with a $12 \mathrm{~V}$ $100 \mathrm{~W}$ tungsten halogen lamp running at $12 \mathrm{~V}$ $(3200 / \mathrm{K})$ and Luminar macro lenses, taking care to use apertures giving even illumination of the whole field. Filtration was unnecessary with the film used, which was Kodak Super Speed 2751 duplicating film. This is a high contrast orthochromatic direct reversal film primarily intended for black and white line duplication. The film was cut to half plate, or $4 \times 5$ inch size $(10.2 \times 12.7 \mathrm{~cm})$. Exposures were equivalent to minus 4.5 DIN. The film was thereafter developed (using Kodak Dektomatic diluted 1 in $\mathbf{4}$ for 2 minutes at $27^{\circ} \mathrm{C}$ ) and fixed (using May and Baker Fixaplus diluted 1 in 3 for 1 minute at $30^{\circ} \mathrm{C}$ ) in an Intercop $1614 \mathrm{VS}$ processor and then washed at $20-25^{\circ} \mathrm{C}$ for 20 minutes.

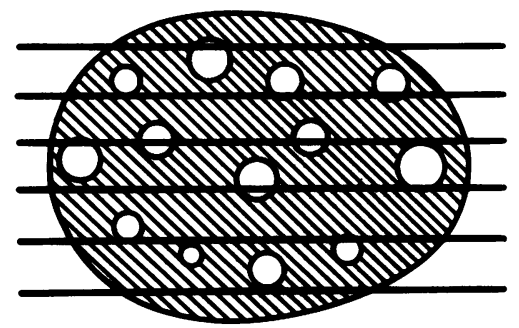

Fig 1 Diagram showing a series of possible longitudinal tracks parallel to the long axis of a lymph node. 


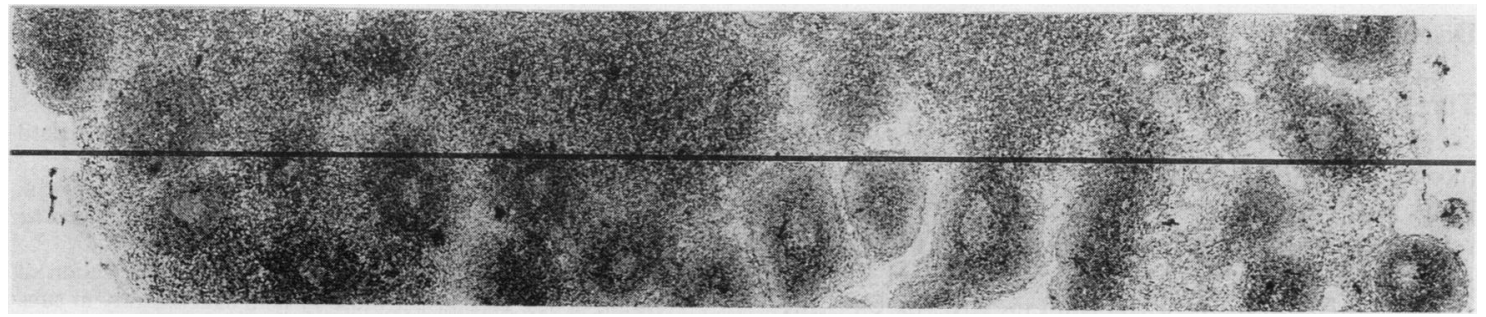

Fig 2 Positive print of a longitudinal track of a reactive lymph node with pronounced follicular hyperplasia and a superimposed $1 \mathrm{~mm}$ scanning line, as viewed by the integrated densitometer. This corresponds to the top trace of nuclear densities in fig 3. (Haematoxylin and eosin).

After thorough air drying at room temperature for 20 minutes the prepared photographic plate films were placed in their longitudinal axis (fig 1) on the horizontally arranged protein track scanning grids of a Gelman ACD-18 automatic computing densitometer. The instrument was set with a range of narrow slit widths between 0.1 and $2.0 \mathrm{~mm}$. The baseline density was set on the perinodal connective tissue, and the optical density range on $90 \%$ Autogain. The optimum scan length for the magnified image of the lymph nodes on the photographic plate was $115 \mathrm{~mm}$. In order to test the quantitative reproducibility the scan length of 10 consecutive scans was manually divided by pencil lines into four equal sectors. The entire procedure-that is, photomicrography, film processing, washing, and the densitometric scanning - took less than one hour for any individual specimen. Batching of the film plates obviously saved more time.

\section{Results}

The linear scans (fig 2) of the optical densities of normal reactive and diseased lymph nodes gave a variety of qualitatively distinctive patterns (fig 3 ). The reactive lymph nodes showed irregular periodic increases of nuclear optical density in the cortical, paracortical, and medullary areas, ${ }^{6}$ whereas there was a more uniform and sustained increase in optical density in nonHodgkin's malignant lymphomas and a skewed distribution of nuclear optical density in focal ischaemia. $^{7}$

All emission wavelengths in the densitometer from 400 to $700 \mathrm{~nm}$ gave identical scan patterns, and the width of the scanning aperture, from 0.1 to $2.0 \mathrm{~mm}$, was found not to be critical. The percentage coefficients of variation ${ }^{8}$ of the integrated densitometric areas of the four fractions from the 10 replicated samples (mean $26 \cdot 49,23 \cdot 30,22 \cdot 76$, and $27 \cdot 45 \%$ ) were $1 \cdot 50,0 \cdot 78,1 \cdot 38$, and 1.46 , respectively.
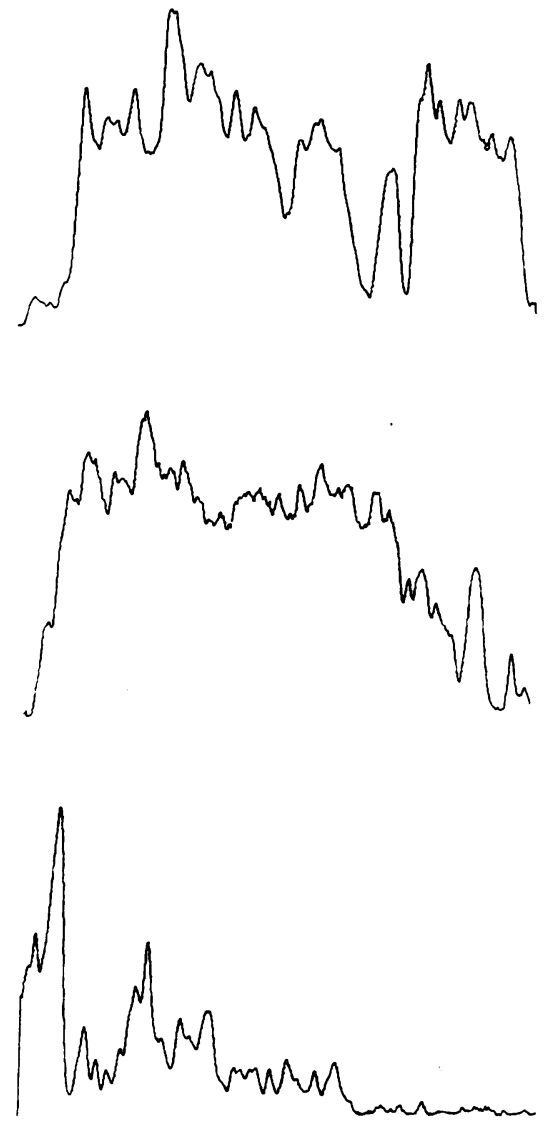

Fig 3 Linear transects of the nuclear optical densities in lymph nodes displaying (from top to bottom): non-specific reactive hyperplasia (see fig 2), a non-Hodgkin's malignant lymphoma, and polar ischaemic loss of cells. 


\section{Discussion}

This novel approach to the measurement of the optical density of linear transects of stained tissue sections has several advantages. It is relatively fast (particularly with batching of the samples for analysis), requires no additional capital expense, is easy to perform, and is not especially labour intensive. Nevertheless, an estimation of the thickness of the sections ${ }^{2}$ at intervals along the chosen plane of the transects is a recommended adjunct to the procedure.

We believe that this method could be useful in other instances when both quantitative and qualitative assessments of optical densities in other anisotropic pathological tissues are required. ${ }^{2}$ The magnification of the tissue is independent of the method. Suitable enlargements of ultrastructural micrographs can be analysed in the same way as images obtained by low power light microscopy. The use of filters in the initial stage of photomicrography may enhance the selectivity of the method, depending on the light absorption characteristics of the dyes used. When studying nuclei stained by haematoxylin, as in our investigation, with a reasonably modest background of eosin this is not necessary when using the red in sensitive film.

\section{References}

1 Underwood EE. Quantitative stereology. Reading, Massachusetts: Addison-Wesley, 1970.

2 Aherne WA, Dunnill MS. Morphometry. London: Edward Arnold, 1982.

3 Baak JPA, Ploem, JS. Equipment for quantative microscopy. In:흘 JPA Baak, J Oort, eds. A manual of morphometry in diagnostic pathology. Berlin: Springer-Verlag, 1983:150.

4 Lucke VM, Davies JD, Wood C. Plexiform vascularization of lymph nodes: an unusual cause of lymphadenopathy in cats. $\tilde{s}$ J Comp Pathol 1987;97:109-19.

5 Maurer R, Schmid U, Davies JD, Mahy NJ, Stansfeld AG, Lukes. RJ. Lymph node infarction and malignant lymphoma: a multi- $\vec{\overrightarrow{ }}$ centre study of European, English and American cases. Histo-W pathology 1986;10:571-88.

6 Roitt IM. Essential immunology. 3rd ed. Edinburgh: Churchillo Livingstone, 1977:70-74.

7 Channer JL, Davies JD. Necrotic lymph nodes and theiro connective-tissue framework. Bristol Med Chir J 1986; 101:42-3.

8 Armitage, P. Statistical methods in medical research. Oxford: Blackwell Scientific, 1971:41

Requests for reprints to: Dr JD Davies, University $\overrightarrow{0}$ Department of Pathology, Bristol Royal Infirmary, Marl-borough Street, Bristol BS2 8HW, England.

\section{Simple technique for fluorescence staining of blood cells with acridine orange}

\section{S A H JAHANMEHR, K HYDE, C G GEARY, K I CINKOTAI, J E MACIVER, University Department of Clinical Haematology, Manchester Royal Infirmary, Manchester}

Fluorescence techniques, which were introduced at the beginning of the century, ${ }^{12}$ are now widely used as a research tool in cytology.

Blood has been studied by several fluorochromes, including auramine and acridine. Acridine orange is the most popular fluorochrome for studies on whole blood, ${ }^{2-6}$ reticulocyte counting, ${ }^{178}$ and identification of nucleic acids..$^{9-11}$ It has also been used in the study of vaginal and cervical cancer, ${ }^{12}$ cell culture, ${ }^{13}$ blood parasites, ${ }^{1415}$ and certain automated techniques. ${ }^{1617}$ The initial object of this study was to develop a more sensitive method for reticulocyte counting. As the study progressed it became clear that the method was also suitable for the

Accepted for publication 12 February 1987 detection of malarial parasites. In addition, it i® possible to identify white cells and to assess red celle morphology in terms of size, shape, and staining intensity.

\section{Material and methods}

Different concentrations of acridine orange solution (Sigma Chemical Company) were tested in a $\mathrm{pH}^{\circ}$ range 5.6-8.2 using a large number of slides with different staining and incubation times. The blood samples were taken from normal subjects and fromt patients with a variety of blood disorders. The following solution of acridine orange gave optimat. cellular staining in the minimum time: acridine orange $0.5 \mathrm{~g}$ and sodium chloride $8.5 \mathrm{~g}$ in 1 litre of distilled water.

The procedure for staining is as follows. Freskw blood $(50 \mu \mathrm{l})$ is delivered into a small clean test tube and an equal volume of the dye solution is added. The tube is then mixed gently for two minutes, after whicl thin smears are made in the usual manner. Rapid drying-for example, using an electric fan-improves the colour development in the cells. The slides are्ष then examined under an oil immersion lens (x40 o? x100 as appropriate) using incident ultraviolet ligh $\mathbb{Q}$ In our experiments this light was produced by $\Phi$ 